\title{
Design and Fabrication of Solar Powered Vapour Absorption Refrigeration System
}

\author{
Varun Yadav $^{1 *}$, Supradeepa Panual G ${ }^{1 *}$, Neeraj Yadav $^{2 *}$, Ratnam Bordia ${ }^{1}$, Rohini Soni ${ }^{1}$ and Rinkesh Khandey ${ }^{1}$ \\ ${ }^{1}$ Dept. of Mechanical Engineering, Medicaps Institute of Tech. and Mgmt., Indore, M.P., India \\ ${ }^{2}$ Dept. of Mechanical Engineering, Medicaps University, Indore, M.P., India
}

\begin{abstract}
Engineering is all about the application of knowledge and ideas for continuous development in society. In today's world, there is a strong need for an environment-friendly refrigerating system, therefore, our focus is on a solar powered vapour absorption refrigeration system. This project focuses on a cooling system that minimizes the dependency over electricity and to show our ability to save our resources for future generations. The objective of this work was to design and fabricate a vapour absorption refrigeration system, using $\mathrm{LiBr}-\mathrm{H}_{2} \mathrm{O}$, as the refrigerants and powered by solar energy. Performance Evaluation of the system has been done on the basis of different operating conditions and parameters like, solar irradiance, collector, generator, condenser and evaporator temperature. The COP of the system was obtained as 0.1 and the capacity was $0.01 \mathrm{TR}$. Since it's an ab-initio development it will be a unique one in terms of understanding and underlying engineering. The system is an eccentric one that can be operated by multiple heat sources like solar energy, biomass etc. without much change in the design. This system can be used to develop an Air Conditioner, Refrigerator or a Chiller
\end{abstract}

\section{Introduction}

Vapour Absorption Refrigeration Systems (VARS) works on the refrigerant absorption principle. It belongs to the category of vapour cycles similar to Vapour Compression Refrigeration Systems (VCRS). However, unlike VCRS, heat is used as an input for the absorption systems. Hence these systems are also called heat operated or thermal energy-driven systems.

The most commonly used pair of refrigerants are Ammonia-Water and LiBr-Water. For Instance, V.K Bajpai's work included a VARS system using $\mathrm{NH}_{3}$ as refrigerant and $\mathrm{H}_{2} \mathrm{O}$ as absorbent. The $\mathrm{COP}$ of the system was found be around 0.58 , when used with flat plate solar collector [1]. In previous research it has been found that the system with $\mathrm{LiBr}$ solution performs better than the system using ammonia solution [2]. This system has been designed as a single effect absorption system as opposed to a double effect system although double effect system has a significantly higher coefficient of performance because of the simplicity and cost-efficiency of a single effect system [3] [4].

There are various ways to provide heat energy as input in the system, the most common methods in case of Solar Energy are Flat Plate Solar Collector, Parabolic Solar Collector and Evacuated tube type Solar Collector. Ajay et al studied the performance of a Vapour Absorption based Air Conditioning System, powered by a parabolic solar collector, with $\mathrm{LiBr}-\mathrm{H}_{2} \mathrm{O}$ being the working fluids. They obtained around $3-4^{\circ} \mathrm{C}$ drop in cabin (evaporator) temperature over the whole working time of the system [5].

Due to high thermal efficiency, higher attainable temperature and less footprint Evacuated tube type collectors are widely used. S Arora et al, studied the thermal analysis of evacuated tube solar collectors, in relation to VARS system [6]. Their work showed that the incident flux of solar radiation and heat transfer coefficient of the air gap in tubes, affects the amount of heat transferred to working fluid. Also, V Mittal et al analysed the effects of collector temperatures on the coefficient of performance (COP) of the system [7].

\section{Working Principle}

VARS has similar working components, except generator and absorber, to that of VCRS. Generator, absorber and pump in VARS work similarly to the compressor present in VCRS. An illustrated single effect VARS system is shown in Fig. 2.1. It should be noted that in $\mathrm{LiBr}$ solution, water act as refrigerant and $\mathrm{LiBr}$ act as the absorbent. The role of absorbent is to enable the flow of refrigerant from the absorber to the generator by absorbing the vapours of refrigerant and forming a solution that can be easily pumped to the generator while consuming significantly less electricity used by the electric VCRS system to compress the refrigerant.

The input energy in the form of thermal energy (1) is added through hot steam and water from a solar water heater/electric heater/gas burner. The thermal energy vaporises the water in $\mathrm{LiBr}$ solution present in the

\footnotetext{
*Corresponding authors: varunyadav1910@gmail.com, gspanual@gmail.com and neeraj.yadav@medicaps.ac.in
} 
generator to steam. The high-pressure steam (2) flows to the condenser leaving strong $\mathrm{LiBr}$ solution in the generator. This pressurised steam then rejects heat to the surrounding and condense to pressurised water (3), which is throttled through an expansion valve to low pressure and temperature liquid water. This low-temperature liquid water flows to the evaporator (4), absorbs the heat from the load and evaporates to vapour state. These water vapours are then sucked in the absorber by the strong $\mathrm{LiBr}$ solution (5), which is throttled down from the generator (6), to form weak $\mathrm{LiBr}$ solution and reject heat in the process. This weak $\mathrm{LiBr}$ solution is then pumped back to the generator (7) to complete the cycle.

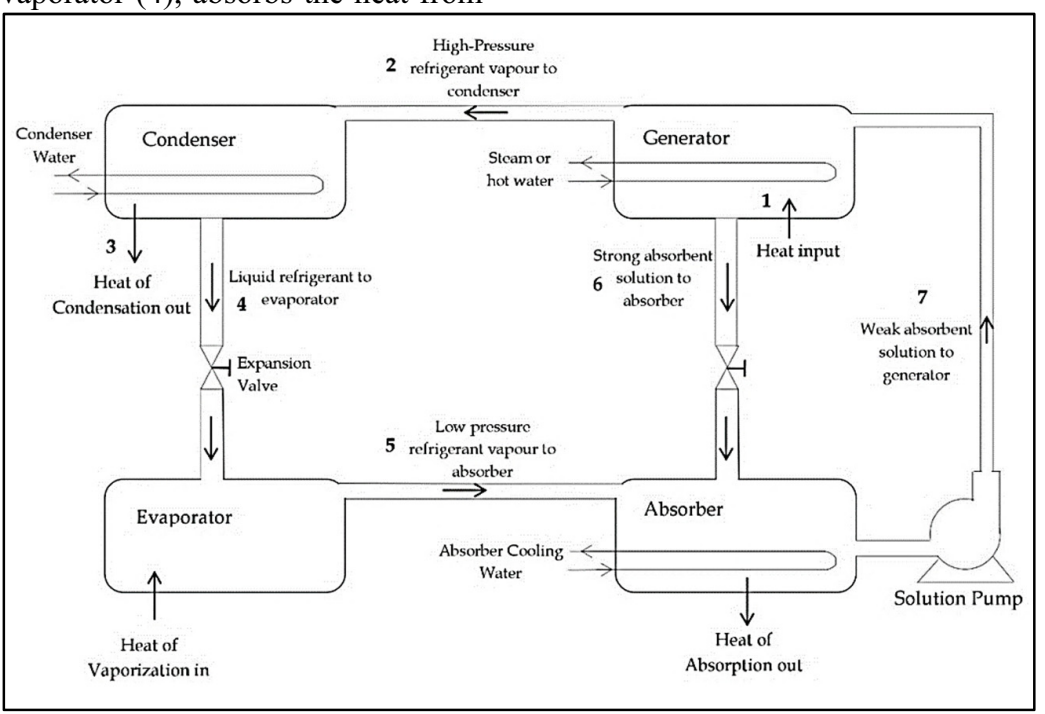

Fig. 2.1. Single Effect Vapour Absorption System

\section{Design of Solar Collector}

The collector designed here is Evacuated tube type Solar Collector. The geographical coordinates of the place for which it is designed are (Latitude: 22.6216 ${ }^{\circ}$; Longitude: $75.8034^{\circ}$ ). The month of operation is assumed to be May. Thus, calculating declination angle and hour angle

$$
\delta=23.45 \sin [360 / 365(284+N)]
$$

$\mathrm{N}=135$ (15th May); Solar daytime $=8$ hours $(9 \mathrm{AM}-5 \mathrm{PM})$

Substituting values in the above equation

$\delta=18.8^{\circ}$

Hour Angle $=\omega$

$\omega=15^{\circ}($ Solar Time- 12$)$

$\omega=37.5^{\circ}$

$\gamma=$ Latitude $=22.62^{\circ}$

Assuming, Solar Constant $=\mathrm{I}_{\mathrm{sc}}=1367 \mathrm{~W} / \mathrm{m}^{2}$

Average Global Horizontal Irradiance $=7.48$ $\mathrm{kWh} / \mathrm{m}^{2} /$ day

Thus, zenith angle can be calculated as,

$$
\operatorname{Cos} z=\sin \gamma \sin \delta+\cos \gamma \cos \delta \cos \omega
$$

$\operatorname{Cos} \mathrm{z}$

$=\sin (22.62) \sin (18.80)$

$+\cos (22.62) \cos (18.80) \cos (37.50)$

$\operatorname{Cos} \mathrm{z}=0.38 \times 0.32+0.92 \times 0.95 \times 0.79$

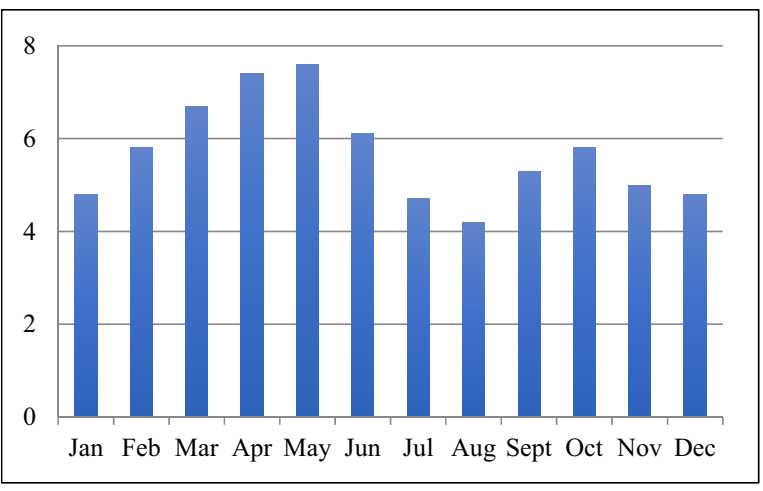

Fig. 3.1. Average Global Horizontal Irradiance $(\mathrm{kWh} / \mathrm{m} 2)$ vs. Month

$\operatorname{Cos} z=0.82$

$z=35.2^{\circ}$

$$
I_{z}=I_{s c} e(-c(\sec z) s)
$$

The value of solar constant is, $\mathrm{I}_{\mathrm{sc}}=1367 \mathrm{~W} / \mathrm{m}^{2}$

Here, $c s=0.2424$

Let,

$60 \% \eta$

Thus, we get, $\mathrm{I}_{\mathrm{z}}=609.66 \mathrm{~W} / \mathrm{m}^{2}$

But practically 
$\mathrm{I}_{\mathrm{z}}=700 \mathrm{~W} / \mathrm{m}^{2}$

Since, $\mathrm{T}_{\mathrm{a}}=37^{\circ} \mathrm{C}, \mathrm{T}_{\mathrm{g}}=92^{\circ} \mathrm{C}, \mathrm{m}_{\mathrm{w}}=5 \mathrm{~kg} \& \mathrm{c}=4.186 \mathrm{~kJ} / \mathrm{kgK}$

Hence heat required for heating the water from $T_{a}$ to $T_{g}$ in an hr

$$
\begin{aligned}
& Q_{\mathrm{i}}=\mathrm{m}_{\mathrm{w}} \times \mathrm{c} \times\left(\frac{\mathrm{T}_{\mathrm{g}}-\mathrm{T}_{\mathrm{a}}}{3600}\right) \\
& Q_{i}=5 \times 4.18 \times\left(\frac{92-37}{3600}\right) \\
& Q_{i}=0.32 \mathrm{~kW}
\end{aligned}
$$

And,

$$
\mathrm{Q}_{\mathrm{i}}=\mathrm{I}_{\mathrm{z}} \times \mathrm{A}
$$

Effective area, $A=\frac{319.3}{700} m^{2}$

$A=0.456 \mathrm{~m}^{2}$

Area of 1 tube $=(\pi \times d \times l) \times 0.52$

$$
\begin{aligned}
& =\pi \times 58 \times 10^{-3} \times 1.8 \times 0.52 \\
& =0.171
\end{aligned}
$$

Number of tubes $=\frac{\text { Effective area }}{\text { Area of } 1 \text { tube }}=\frac{0.456}{0.171} \approx 3$

\section{Design of VARS system}

\subsection{Heat absorbed in Generator $\left(Q_{G}\right)$ :}

A Generator is a heat exchanger to give heat energy as input to the VARS system. In this system, we have used a shell and tube type heat exchanger due to its simple and cost-effective structure. A considerable amount of research has been done on the boiling of liquids but data on $\mathrm{LiBr}$ solution is not extensive. It has been found that the average heat transfer coefficient lies between 1600 $\mathrm{W} / \mathrm{m}^{2} \mathrm{~K}$ and $7500 \mathrm{~W} / \mathrm{m}^{2} \mathrm{~K}[8]$.

$$
Q_{G}=\mathrm{hA}(\mathrm{T} \infty-\mathrm{Ts})
$$

$Q_{G}=3200 \times(3.14 \times 0.02 \times 0.32) \times(95-90)$

$Q_{G}=323.55 \mathrm{~W}$

\subsection{Heat absorbed in Evaporator $\left(Q_{E}\right)$ :}

Dimensions of evaporator cabin: $48 \times 36 \times 25 \mathrm{~cm}^{3}$; Thickness of evaporator cabin: $2 \mathrm{~cm}$; Thermal conductivity: $0.04 \mathrm{~W} / \mathrm{mK}$.

The cabin is made up of polystyrene which is a thermal insulator with low thermal conductivity. Assuming laminar flow around all the surface, we can use simplified equation for air:

Vertical Plate

$$
h_{v}=1.42 \times(\Delta T / L)^{1 / 4}
$$

Cabin temperature $=\mathrm{T}_{\mathrm{e}}=10^{\circ} \mathrm{C}$
Inside surface temperature $=\mathrm{T}_{\mathrm{i}}=17^{\circ} \mathrm{C}$

Outside Surface temperature $=\mathrm{T}_{\mathrm{o}}=35^{\circ} \mathrm{C}$

Ambient temperature $=\mathrm{T}_{\mathrm{a}}=37^{\circ} \mathrm{C}$

$h_{v a}=1.42 \times\left(\frac{37-35}{0.48}\right)^{1 / 4}=2.03 \mathrm{~W} / \mathrm{m}^{2} \mathrm{~K}$

$h_{v b}=1.42 \times\left(\frac{17-10}{0.48}\right)^{1 / 4}=2.77 \mathrm{~W} / \mathrm{m}^{2} \mathrm{~K}$

Similarly, for horizontal plate

$$
h_{h}=1.32 \times(\Delta T / L)^{1 / 4}
$$

$h_{h a}=1.32 \times\left(\frac{37-35}{0.36}\right)^{1 / 4}=2.03 \mathrm{~W} / \mathrm{m}^{2} \mathrm{~K}$

$h_{h b}=1.32 \times\left(\frac{17-10}{0.36}\right)^{1 / 4}=2.77 \mathrm{~W} / \mathrm{m}^{2} \mathrm{~K}$

Heat absorbed from Front and Back walls of evaporator:

$$
Q_{e 1}=\frac{2 \times\left(T_{a}-T_{e}\right)}{\left[\left(1 / h_{v a}\right)+\left(l / k A_{1}\right)+\left(1 / h_{v b}\right)\right]}
$$

$Q_{e 1}=\frac{2 \times(37-10)}{[(1 / 2.03)+(0.02 /(0.04 \times 0.12))+(1 / 2.77)]}$

$Q_{e 1}=\frac{2 \times 27}{5.02}=10.76 \mathrm{~W}$

Similarly, for Top \& Bottom walls of evaporator:

$$
\begin{gathered}
Q_{e 2}=\frac{2 \times\left(T_{a}-T_{e}\right)}{\left[\left(1 / h_{h a}\right)+\left(l / k A_{2}\right)+\left(1 / h_{h b}\right)\right]} \\
Q_{e 2}=\frac{2 \times(37-10)}{[(1 / 2.03)+(0.02 /(0.04 \times 0.17)+(1 / 2.77)]} \\
Q_{e 2}=\frac{2 \times 27}{3.75}=14.41 \mathrm{~W}
\end{gathered}
$$

Side walls:

$$
\begin{gathered}
Q_{e 3}=\frac{2 \times\left(T_{a}-T_{e}\right)}{\left[\left(1 / h_{v a}\right)+\left(l / k A_{3}\right)+\left(1 / h_{v b}\right)\right]} \\
Q_{e 3}=\frac{2 \times(37-10)}{[(1 / 2.03)+(0.02 /(0.04 \times 0.09)+(1 / 2.77)]} \\
Q_{e 3}=\frac{2 \times 27}{6.41}=8.43 \mathrm{~W} \\
Q_{E}=Q_{e 1}+Q_{e 2}+Q_{e 3} \\
Q_{E}=33.59 \mathrm{~W}
\end{gathered}
$$

\section{Coefficient of Performance:}

$C O P=\frac{Q_{E}}{Q_{G}}=\frac{33.59}{323.55}=0.10$

\section{Tonnage of Refrigerator:}

Heat due to infiltration, 


$$
\begin{gathered}
Q_{i}=\frac{\left[q \times\left(\frac{1}{v_{1}}\right) \times\left(h_{1}-h_{2}\right)\right]}{60} \mathrm{~kW} \\
q=\frac{L \times W \times H \times A_{c}}{60} \mathrm{~m}^{3} / \mathrm{min} \\
A_{c}=A_{c 1}+A_{c 2}=0.5+2=2.5 \quad \operatorname{Refer}[9,10] \\
q=\frac{0.48 \times 0.36 \times 0.25 \times 2.5}{60}=1.8 \times 10^{-3} \mathrm{~m}^{3} / \mathrm{min}
\end{gathered}
$$

Outside Conditions:

At $\mathrm{T}_{\mathrm{a}}=37^{\circ} \mathrm{C} \& \mathrm{RH}=10 \%$

$\mathrm{h}_{1}=47.22 \mathrm{~kJ} / \mathrm{kg} ; \mathrm{v}_{1}=0.89 \mathrm{~m}^{3} / \mathrm{kg}$

Inside cabin conditions:

At $10^{\circ} \mathrm{C} \& \mathrm{RH}=60 \%$

$\mathrm{h}_{2}=21.58 \mathrm{~kJ} / \mathrm{kg} ; \mathrm{v}_{2}=0.81 \mathrm{~m}^{3} / \mathrm{kg}$

$Q_{i}=1.8 \times 10^{-3} \times\left(\frac{1}{0.89}\right) \times(47.22-21.58) \mathrm{kJ} / \mathrm{min}$

$Q_{i}=0.87 \mathrm{~W}$

Since,

$$
\text { Total Cooling Load }(T C L)=Q_{E}+Q_{i}
$$

$$
T C L=33.59+0.87=34.46 W
$$

$$
\text { Tonnage of Refrigeration }=\frac{T C L}{3.52 \times 10^{3}}
$$

$$
=\frac{34.46}{3.52 \times 10^{3}}=0.01 \mathrm{TR}
$$

\section{Construction}

\subsection{Condenser:}

Air-cooled fin type condenser (Fig. 5.1) with $0.375 \mathrm{~mm}$ outer diameter (OD) and $225 \mathrm{~mm}$ length of copper tube was used to condense the refrigerant and cool it down further. The refrigerant flows inside the copper tube and fins are soldered on the surface of the copper tube so that it increases the overall contact surface area for heat transfer. Finned type condenser has better efficiency than bare tube type condenser and is economical than shell and tube type condenser which makes it convenient to use and maintain.

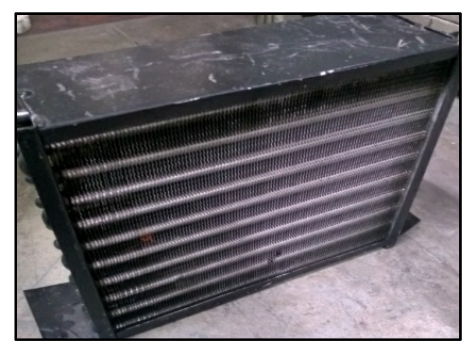

Fig. 5.1. Air-Cooled fin type condenser

\subsection{Evaporator:}

The chilled refrigerant after throttling enters the insulated polystyrene evaporator casing (Fig. 5.3), of length $48 \mathrm{~mm}$, breadth $36 \mathrm{~mm}$ and height $25 \mathrm{~mm}$, in the copper tube (OD $=0.625 \mathrm{~mm}$ ). This copper tube (Fig. 5.2) is bent so that the length of the copper tube inside the evaporator casing could be increased which in turn increases the effective surface area for heat to be transferred from the load eventually to the refrigerant.

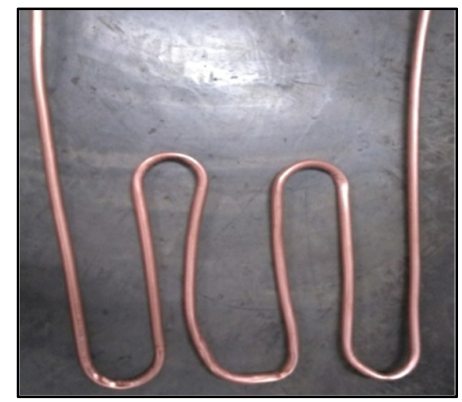

Fig. 5.2. Evaporator coil

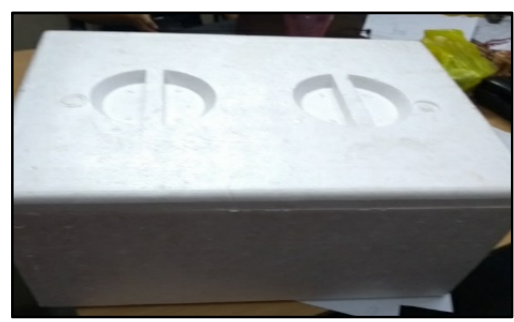

Fig. 5.3. Evaporator Casing

\subsection{Absorber:}

When water from the evaporator enters the absorber, it is absorbed by the absorbent, this process is exothermic and hence heat is released. This heat increases the temperature in the absorber. Several pieces of research have observed that with the increase in temperature of absorber the COP of the system reduces significantly [11], hence the most widely used method of absorption of vapor refrigerant into a falling film of solution over cooled horizontal tubes is used to reduce the temperature inside the absorber.

A copper tube of $(\mathrm{OD}=0.625 \mathrm{~mm})$ with precisely drilled holes is placed on top of an array of horizontal copper tubes $(\mathrm{OD}=0.375 \mathrm{~mm})$ bent from a single pipe such that all of them are connected. The strong $\mathrm{LiBr}$ solution flows through the tube at the top and drips down the holes on to the array of horizontal absorber tubes with cooling water flowing through them. The refrigerant flows to the evaporator through a tube to the absorber, where it is absorbed by the absorbent in the solution. This whole setup is enclosed in non-reactive and anti-corrosion high-density polythene cylindrical container. 


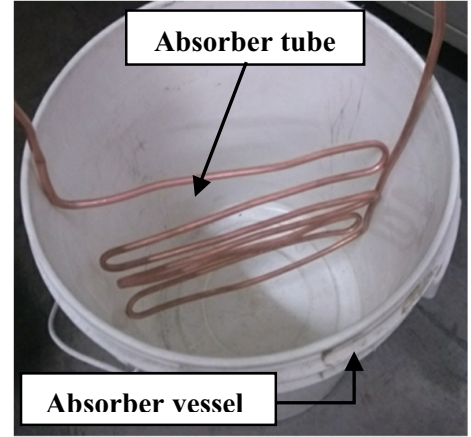

Fig. 5.4. Absorber

\subsection{Generator:}

The generator is made with galvanized iron plates welded together to form a cuboidal box (Fig. 5.5) of dimension $15 \times 15 \times 30 \mathrm{~mm}$. LiBr solution is heated in this box with the help of hot water, from the solar collector, flowing inside the helix-shaped copper tube (Fig. 5.6) of OD $=0.375 \mathrm{~mm}$. The box is insulated with a thick asbestos sheet to maintain the high temperature inside the generator.

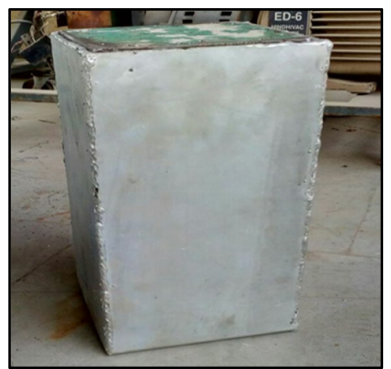

Fig. 5.5. Generator vessel

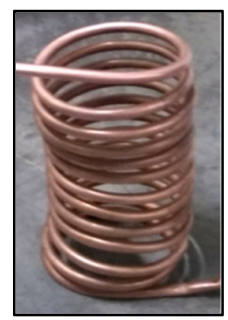

Fig. 5.6. Generator heating coil

\subsection{Evacuated Tube Solar Collector:}

Three evacuated tubes of length $1.8 \mathrm{~m}$ and OD $58 \mathrm{~mm}$ are placed parallel to each other on a stand. A small container is fitted at the top of the collector with the top end of each of the three tubes connected to the container (Fig. 5.7). The tubes are placed at an angle of $10^{\circ}$ (around $20^{\circ}$ less than the latitude) to maximise the annual energy collection [12].
Table 1. General Parameter of Evacuated Tube Collector

\begin{tabular}{|c|c|}
\hline Parameters & Value \\
\hline Tube length & $1800 \mathrm{~mm}$ \\
\hline Tube Diameter, (Outer) & $58 \mathrm{~mm}$ \\
\hline Absorptive Coating Material & $\mathrm{Cu} / \mathrm{SS}-\mathrm{ALN}$ \\
\hline Glass Material & Borosilicate Glass 3.3 \\
\hline Vacuum Range & $<=5 * 10^{-3} \mathrm{~Pa}$ \\
\hline $\begin{array}{c}\text { Total No. Of tubes used in the } \\
\text { collector }\end{array}$ & 3 \\
\hline
\end{tabular}

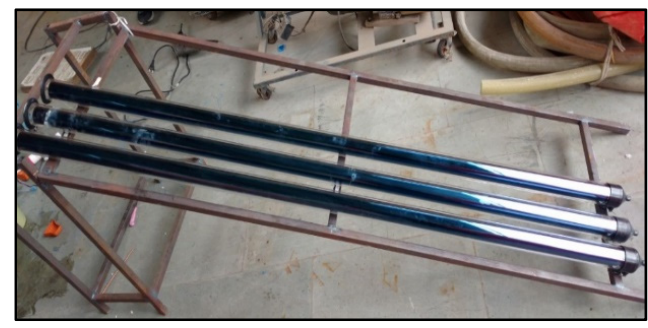

Fig. 5.7. Evacuated tube type solar collector

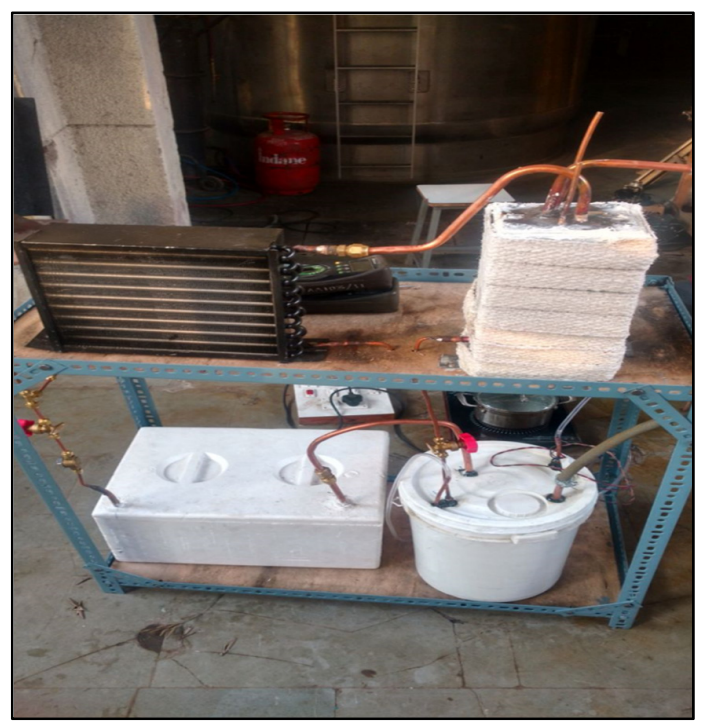

Fig. 5.8. Experimental setup of VARS using solar thermal energy

\section{Observation \& Result}

The evacuated tube type solar collector was tested for around $2.5 \mathrm{hrs}$, on an average sunny day (04/04/2018) at $11: 30$ am and the temperature corresponding to the time taken was measured and tabulated below.

Table 2. Collector fluid temperature vs Time

\begin{tabular}{|c|c|c|}
\hline S. No. & Temperature $\left({ }^{\circ} \mathbf{C}\right)$ & Time (in min) \\
\hline 1 & 32.7 & 0 \\
\hline 2 & 35.6 & 4 \\
\hline 3 & 40.9 & 8 \\
\hline 4 & 42.1 & 12 \\
\hline 5 & 43.6 & 16 \\
\hline 6 & 49.2 & 24 \\
\hline
\end{tabular}




\begin{tabular}{|c|c|c|}
\hline 7 & 55.6 & 32 \\
\hline 8 & 61.1 & 40 \\
\hline 9 & 65.8 & 48 \\
\hline 10 & 72.3 & 60 \\
\hline 11 & 78.2 & 72 \\
\hline 12 & 81.8 & 84 \\
\hline 13 & 84.5 & 96 \\
\hline 14 & 86.8 & 108 \\
\hline 15 & 89.2 & 120 \\
\hline 16 & 91.6 & 132 \\
\hline 17 & 93.8 & 144 \\
\hline 18 & 94.8 & 156 \\
\hline
\end{tabular}

Evaporator temperature corresponding to the generator temperature was measured at 3 millibar pressure (maintained with the help of a vacuum pump). In the course of testing for $4 \mathrm{hrs}$, a maximum drop of $20^{\circ} \mathrm{C}$ was achieved (Fig. 6.2).

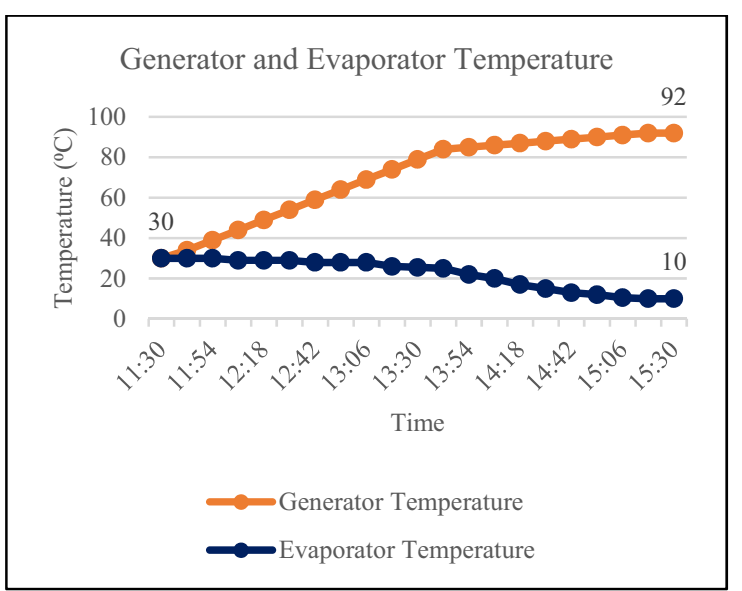

Fig. 6.2. Generator and Evaporator Temperature

\section{Conclusion}

A vapour absorption refrigeration system was designed and fabricated, with $\mathrm{LiBr}-\mathrm{H}_{2} \mathrm{O}$ as the working fluid and to be able to be powered by renewable and sustainable heat energy sources. An evacuated tube solar collector was designed for delivering the required power to the system. It was found that the collector was able to reach a temperature of around $92^{\circ} \mathrm{C}$ in a couple of hours, which in turn facilitated the system such that, a temperature difference of the order $18-20^{\circ} \mathrm{C}$ was found in the evaporator (cabin) as compared to the ambient temperature. The COP of the system was calculated to be 0.1 and the capacity of the system was computed to be $0.01 \mathrm{TR}$.

Based on the observation it's conclusive that this system can be used as a viable sustainable alternative to conventional refrigeration systems. The low running cost is an additional cost-benefit for the consumer and since it requires heat energy as input it can be used in remote areas with limited access to electricity. This unit offers an approach to provide billions of people with access to lowcost refrigeration medium while contributing significantly to curb climate change.

Authors thank the Director and HoD of Mechanical Engineering of Medicaps Inst. of Tech. and Mgmt for their support. We thank Dr. V. Ganesan (Director, UGC-DAE CSR Indore) for his encouragement., M.P. Saravanan, Dr. M.M. Patidar, Mr. N. Vijayakumar and the members of Cryogenics Lab of CSR Indore deserve special thanks for their guidance and support.

\section{References}

1. V. Bajpai, in Proceedings of the World Congress on Engineering (2012), pp. 4-6

2. I. Horuz, International Communications in Heat and Mass Transfer 25, 711 (1998)

3. L. Dominguez-Inzunza, J. HernándezMagallanes, M. Sandoval-Reyes, and W. Rivera, Applied Thermal Engineering 66, 612 (2014)

4. C. B. Dorgan, C. E. Dorgan, and S. P. Leight, ASHRAE Journal 37, (1995)

5. N. Ajay Sankar and D. S. Sankar, International Journal of Innovative Research in Science, Engineering and Technology (An ISO 3297: 2007 Certified Organization) 4, (2015)

6. S. Arora, S. Chitkara, R. Udayakumar, and M. Ali, Journal of Petroleum and Gas Engineering 4, 74 (2011)

7. V. Mittal, K. Kasana, and N. Thakur, Journal of Energy in Southern Africa 17, 65 (2006)

8. H. Varma, R. Mehrotra, K. Agrawal, and S. Singh, International Communications in Heat and Mass Transfer 21, 539 (1994)

9. A. Handbook and others, ASHRAE Handbook, Fundamentals (2007)

10. K. Karthik, International Journal of Emerging Technology and Advanced 
Engineering 4, (2014)

11. B. Babu and G. M. P. Yadav,

International Journal of Engineering

Research and Management (IJMERM)

ISSN 2349 (2015)

12. M. Jamil Ahmad and G. N Tiwari, The Open Renewable Energy Journal 2, (2009) 